\title{
All weather IASI single field-of-view retrievals: case study - validation with JAIVEx data
}

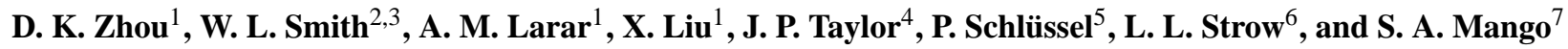 \\ ${ }^{1}$ NASA Langley Research Center, Hampton, VA, USA \\ ${ }^{2}$ Hampton University, Hampton, VA, USA \\ ${ }^{3}$ University of Wisconsin-Madison, Madison, WI, USA \\ ${ }^{4}$ Met Office, Exeter, Devon, UK \\ ${ }^{5}$ EUMETSAT, Darmstadt, Germany \\ ${ }^{6}$ University of Maryland Baltimore County, Baltimore, MD, USA \\ ${ }^{7}$ NPOESS Integrated Program Office, Silver Spring, MD, USA
}

Received: 7 October 2008 - Published in Atmos. Chem. Phys. Discuss.: 16 December 2008

Revised: 17 February 2009 - Accepted: 16 March 2009 - Published: 27 March 2009

\begin{abstract}
Atmospheric thermodynamic parameters, such as atmospheric temperature and moisture profiles, cloud opti$\mathrm{cal} /$ microphysical properties, and surface properties are basic meteorological variables for weather forecasting. In addition, they are critical parameters in tropospheric chemistry studies. A physical, geophysical parameter retrieval scheme dealing with cloudy and cloud-free radiances observed with satellite ultraspectral infrared sounders has been developed to determine simultaneously surface, atmospheric thermodynamic, and cloud microphysical parameters. A one-dimensional variational (1-D Var.) multivariable inverse solution of the radiative transfer equation is used to iteratively improve a background state defined by eigenvector regression. This algorithm has been applied to data from the Infrared Atmospheric Sounding Interferometer (IASI) on the EUMETSAT Metop-A satellite. The IASI retrieved parameters presented herein are from radiance data gathered during the Joint Airborne IASI Validation Experiment (JAIVEx). JAIVEx provided intensive aircraft observations obtained from airborne Fourier Transform Spectrometer (FTS) systems, such as the NPOESS Airborne Sounder Testbed - Interferometer (NAST-I), in-situ measurements, and dedicated dropsonde and radiosonde measurements for the validation of the IASI products. Here, IASI atmospheric profile retrievals are compared with those obtained from dedicated dropsondes, radiosondes, and the airborne FTS system. The
\end{abstract}

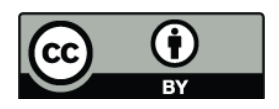

Correspondence to: D. K. Zhou (daniel.k.zhou@nasa.gov)
IASI examples presented here demonstrate the ability to retrieve fine-scale horizontal features with high vertical resolution from satellite ultraspectral sounder radiance spectra.

\section{Introduction}

Atmospheric and surface thermodynamic parameters retrieved with advanced ultraspectral remote sensors aboard Earth observing satellites are critical to general atmospheric and Earth sciences research, climate monitoring, and weather prediction. The Earth Observing System (EOS) Aqua satellite with the Atmospheric InfraRed Sounder (AIRS) on board was launched on 4 May 2002 (e.g., Pagano et al., 2003; Aumann et al., 2003). Satellite ultraspectral data (such as from AIRS) has been shown to be significant for atmospheric research and monitoring our Earth environment (e.g., Chahine et al., 2006, Eldering et al., 2004). The IASI (e.g., Blumstein et al., 2004), on the Metop-A satellite (Klaes et al., 2007), launched on 19 October 2006, is the first of the advanced ultraspectral resolution temperature, humidity, and trace gas sounding instruments being flown as part of the Initial Joint Polar System (IJPS) of POES (U.S. Polar Orbiting Environmental Satellites) and EPS (EUMETAT Polar System) programs, the precursor of the Joint Polar System (JPS) of NPOESS (National Polar-orbiting Operational Environmental Satellite System) and EPS operational satellites for the purpose of improved weather, climate, and air quality observation and forecasting. IASI possesses a high spectral resolution of $0.25 \mathrm{~cm}^{-1}$ and a spectral coverage from 645 to

Published by Copernicus Publications on behalf of the European Geosciences Union. 
$2760 \mathrm{~cm}^{-1}$. The retrieval algorithms for these satellite instruments and their retrieved parameters must be validated to demonstrate the capability and accuracy of both observation and data processing systems.

Fast molecular and cloud transmittance models have been used to enable the exploitation of infrared radiances under cloudy conditions with the accuracy required for sounding retrievals. The empirical orthogonal function (EOF, or eigenvector) statistical regression retrieval algorithm has been expanded to include realistic cloud parameters (e.g., cloud top height, effective particle diameter, and optical thickness) to enable atmospheric profile retrieval using cloudy as well as cloud-free observations (Smith et al., 2004; Zhou et al., 2005). Cloud parameters as well as atmospheric profiles are simultaneously retrieved from infrared (IR) spectral radiance observations with the initially developed EOF regression algorithm using the NPOESS Airborne Sounder Testbed Interferometer (NAST-I) (Cousins and Smith, 1997). The NAST-I fast transmittance model is a combination of the Optimal Spectral Sampling (OSS) fast molecular radiative transfer model (Moncet et al., 2003; Liu et al., 2003) and the physically based cloud radiative transfer model based on the DIScrete Ordinate Radiative Transfer (DISORT) (Stamnes et al., 1988) calculations performed for a wide variety of cloud microphysical properties (Yang et al., 2001). A onedimensional variational (1-D Var.) multi-variable inversion solution was added to improve an iterative background state defined by an eigenvector-regression-retrieval in order to account for nonlinearity in the 1-D variational solution (Zhou et al., 2007a). It is shown that temperature and moisture retrievals can be achieved below optically thin clouds. For optically thick clouds, accurate temperature and moisture profiles down to cloud-top level are obtained. For both optically thin and thick cloud situations, the cloud-top height $\left(\mathrm{H}_{c}\right)$ can be retrieved with high accuracy. The retrieval algorithm was first validated using NAST-I radiance spectra and coincident observations obtained from dropsondes and the nadir-pointing Cloud Physics Lidar (CPL) during The Observing System Research and Predictability Experiment (THORPEX) Atlantic Regional Campaign. The EOF regression based algorithm has also been applied to the data of AIRS instrument, being flown on the Aqua satellite. Successful retrieval results were obtained in partially cloudy cases (Weisz et al., 2007).

Retrieval algorithm development in conjunction with its performance validation is critical for the production of useful atmospheric and surface geophysical parameters as well as for the development of data-processing algorithms for future satellite instruments, such as the NPOESS Cross-track Infrared Sounder (CrIS), and for demonstrating the use of the retrievals for improving numerical weather prediction. The retrieval algorithm developed with NAST-I has been adapted with a globally representative training database for EOF regression and applied to the IASI data, as well as the AIRS data, to fulfill the need for a global coverage of at- mospheric profiles. This paper presents atmospheric profile results based on the single field-of-view retrieval system applied to the IASI and AIRS spectral radiance measurements during the Joint Airborne IASI Validation Experiment (JAIVEx). Profile retrievals are validated through comparisons with profiles observed with dedicated dropsondes, radiosondes, and those determined from the NAST-I airborne Fourier Transform Spectrometer (FTS) system. The capability of satellite ultraspectral IR remote sensors to observe fine-scale horizontal thermodynamic features with high vertical resolution is demonstrated.

\section{Retrieval Algorithm and Performance Analysis}

The retrieval algorithm described herein only uses IR radiance spectra from instruments such as IASI or AIRS; no other data from satellite or surface-based instruments nor from numerical weather analysis/prediction models is utilized in assisting or constraining the retrieval products. The IASI and AIRS fast transmittance model used herein is a combination of the Stand-alone AIRS Radiative Transfer Algorithm (SARTA) Version 1.07 (Strow et al., 2003) and the physically-based cloud radiative transfer model based on the DISORT (Stamnes et al., 1988). Calculations are performed for a wide variety of cloud microphysical properties (Yang et al., 2001). The retrieval algorithm used for both IASI and AIRS is based on that first developed and demonstrated with NAST-I using an EOF regression training database that consists of 15150 profiles obtained from the SeeBor database (e.g., Borbas et al., 2005; Weisz et al., 2007; Seemann et al., 2008). The profile vertical pressure grid consists of 101 levels as defined by SARTA. The surface emissivity spectrum used with each training profile is randomly selected from a set of laboratory measured emissivity spectra for a wide variety of surface types (Salisbury and D'Aria, 1992). The cloud microphysical properties are also simulated. A random number generator is used to specify cloud visible optical thickness equally distributed within a pre-specified range. A parameterization based on the balloon and aircraft cloud microphysical database (Heymsfield et al., 2003) is used to specify cloud effective particle diameter $\left(\mathrm{D}_{e}\right)$ from the cloud optical thickness (COT). Details are found in Zhou et al. (2005). An iterative onedimensional variational (1-D Var.) multi-variable inversion using the minimum-information regularization method (e.g., Twomey, 1963; Tikhonov, 1963; Rodgers, 1976; Hansen, 1998) is used for obtaining the final retrieval in this system. Initially, our cloudy EOF regression retrieval was developed for application to localized and seasonally limited aircraft data gathering campaigns. For this application, a seasonally localized training with altitude-classified cloudy regression was made to constrain non-linear atmospheric and cloud retrievals. To apply these algorithms to radiance measurements from satellite instruments, an all-season global EOF 
regression database is used to obtain the initial profile for the 1-D Var. physical retrieval. The physical iterative retrieval can effectively, but not fully, account for non-linearity and further improves retrieval accuracy from the initial profile produced by EOF linear regression. An altitude-classified cloudy regression is replaced by an all-altitude cloudy regression thereby reducing the number of required regression coefficients. However, the regression coefficients are still classified with respect to cloud-free and cloudy conditions. The algorithm and details are found elsewhere (Zhou et al., 2005; Zhou et al., 2007a). Based on experience with NAST-I, it is desirable to use as many spectral samples of the measured spectrum as possible in the retrieval process. For IASI, some spectral samples are excluded from the retrieval based on lack of a priori knowledge of contaminating trace gases and instrument noise level (Zhou et al., 2002). The weighting functions (i.e., Jacobians) can be calculated by an analytical scheme or a numerical perturbation method (e.g., Li, 1994; Ma et al., 1999). The weighting functions associated with water vapor and constant mixing ratio gases have peaks distributed throughout the range of pressure altitude. In other words, these spectral channels (indicated in Fig. 1b) can be used for temperature and water vapor profile retrieval. These weighting functions are also used to select the spectral samples for the physical retrieval. The IASI retrieval presented herein uses 5008 spectral samples for the EOF regression retrieval and 1697 samples for the second step physical retrieval, as indicated in Fig. 1. Channel selection criteria are very similar to that of NAST-I described by Zhou et al. (2002). The measured channel-radiances used for physical retrieval have gone through EOF-reconstruction using synthetic EOFs to reduce overall random noise and filter spectral shift noise due to a non-uniform field of view (e.g., that produced by non-uniform cloud cover). This also allows building compatibility between the measured radiance spectrum and the radiative transfer based Jacobians used in the physical retrieval.

Retrieval accuracy cannot be precisely determined for this type of "ill-posed" solution but can be estimated by taking advantage of radiative transfer model simulation in obtaining synthetic observed radiances. Some pre-launch retrieval analyses for IASI have been performed by Aires et al. (2002), who did the analysis with a constant surface emissivity under clear-sky oceanic conditions. The "true" profile (i.e., the radiosonde observation) is known and the retrieval can be directly compared with the truth to define retrieval accuracy due to; (1) instrumental noise and (2) retrieval error introduced by the so-called "ill-posed" retrieval model. The disadvantage of this approach is that errors in the forward radiative transfer model are not included. However, detailed validation in estimating both forward and inversion model errors can be fulfilled with dedicated field campaigns. Here, atmospheric conditions are coincidently captured by multiple instruments from both ground and aircraft validation sites (e.g., Zhou et al., 2007b; Taylor et al., 2008), where dedi- (a) Regression channels

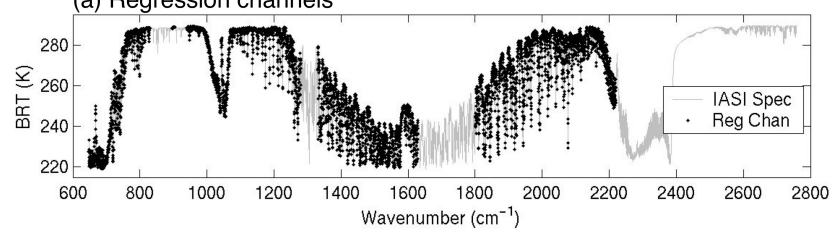

(b) Physical channels

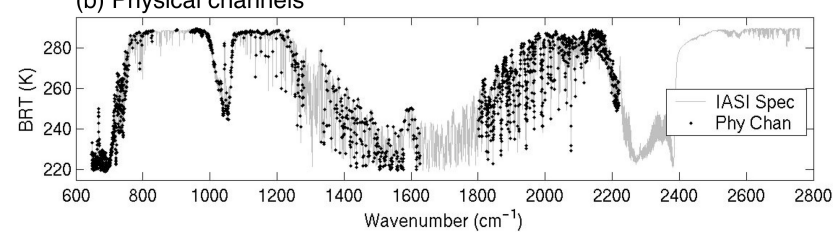

Fig. 1. Retrieval channels used for (a) EOF regression (5008 channels) and (b) 1-D variational multi-variable inversion (1697 channels).

cated coincident radiosondes were launched under satellite overpasses for a reasonable period (e.g., Tobin et al., 2006; Pougatchev, 2008). This atmospheric profile retrieval is a solution of an "ill-posed" problem and its retrieval accuracy is measurement or scene dependent. Thus, it is important to estimate retrieval accuracy through global synthetic simulations, intensive field campaigns, and validations. The retrieval accuracy analysis with a single field-of-view (FOV) retrieval algorithm reported here has been performed through synthetic simulations with IASI instrumental noise over a global dataset for both cloud-free and cloudy conditions. A test dataset is used to simulate IASI observations for physical retrieval performance analysis. It is noted that this kind of error analysis is dependent on the test dataset; however, the analysis can be done over a large set of samples to minimize the bias of the test dataset. Since the absolute retrieval error is observation or scene dependent, retrieval accuracy is represented by the mean difference (i.e., bias) and the standard deviation of the error (i.e., STDE) over a global dataset in three separate categories: (1) clear-sky over water, (2) clear-sky over land, and (3) cloudy conditions. Key thermodynamic parameters, such as atmospheric temperature profile, moisture profile, surface skin temperature and emissivity (for cloud-free cases) or cloud microphysical parameters (for cloudy cases), are used to indicate retrieval accuracy over a global dataset.

For cloud-free conditions, Fig. 2a-c show statistical results for temperature and moisture profiles retrieved from sample locations indicated in Fig. 2d. It is worth mentioning that this analysis is for an extremely diverse dataset including the regions (i.e., polar, high terrain/mountains, and barren) where retrievals normally have difficulties reaching the desired accuracy as can be obtained for some other regions (e.g., tropical oceanic). Retrieved profile accuracy, shown in Fig. 2a-c, is what we expect from this retrieval algorithm for a global coverage. A relatively large retrieval uncertainty is 

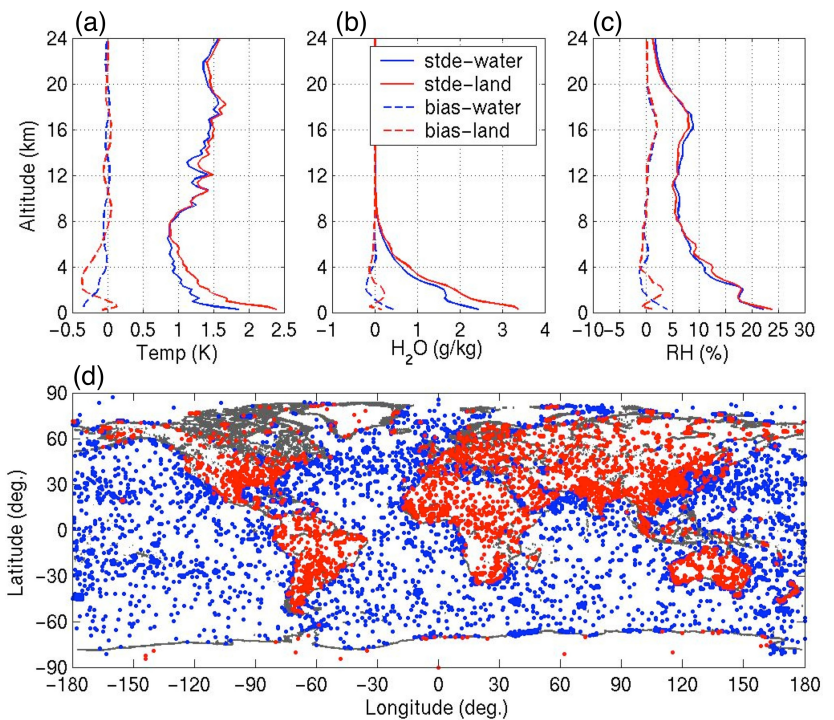

Fig. 2. Retrieval error analysis over IASI simulated clear-sky observations. Panels (a-c) are the bias and STDE of temperature and moisture profiles for observations over water (blue curves) and land (red curves); and associated geophysical locations of the observations are indicated in panel (d) over water (blue dots) and land (red dots).
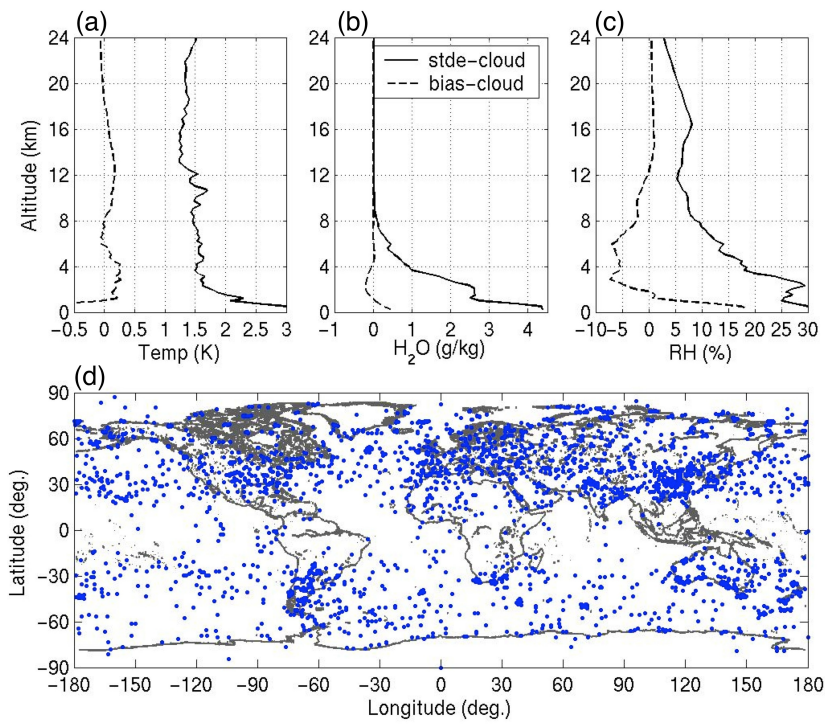

Fig. 3. Retrieval error analysis over IASI simulated cloudy observations. Panels $(\mathbf{a}-\mathbf{c})$ are the bias and STDE of temperature and moisture profiles and associated geophysical locations of the observations are indicated in panel (d).

noticed in the boundary layer for both temperature and moisture profilers which is due to (1) lower retrieval sensitivity in the boundary layer, dependent on surface skin temperature contrast with the surface air temperature, (2) retrieved surface parameter (skin temperature and emissivity) uncertain- (a)

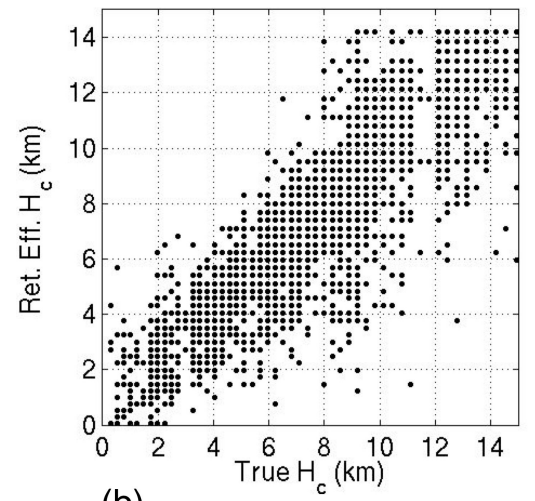

(b)

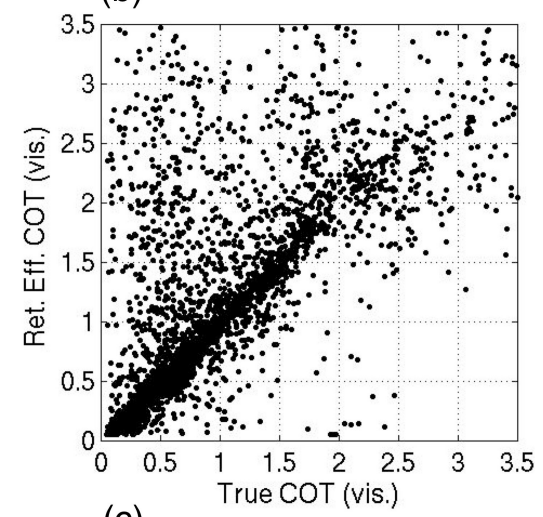

(c)

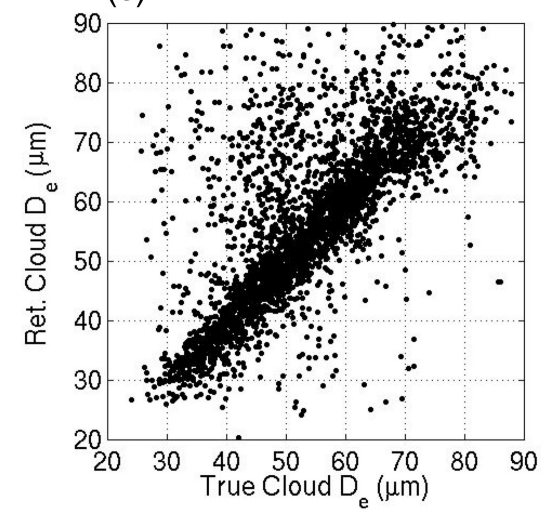

Fig. 4. Retrieved cloud parameter plotted against the truth: Hc, COT, and De (see text) are in panels (a-c), respectively.

ties, and (3) the complexity of boundary layer structure and variation. The STDE and bias of surface skin temperature $\left(T_{S}\right)$ are listed in Table 1. Under cloudy conditions, Fig. 3ac show statistical results for temperature and moisture profiles retrieved from sample locations indicated in Fig. 3d. The corresponding retrieval accuracy is shown in Fig. 3ac. The associated cloud parameters (i.e., $\mathrm{H}_{c}$, COT, and $\mathrm{D}_{e}$ ) are plotted in Fig. 4 and overall STDE and bias of these parameters are given in Table 1. In general, atmospheric and surface parameters are retrieved with an expected accuracy for both clear and cloudy conditions, in comparison with the 
Table 1. Surface temperature and cloud parameters retrieval error statistics relative to "truth".

\begin{tabular}{lccc}
\hline & Clear over water & Clear over land & Cloudy \\
\hline No. of Samples & 6262 & 5868 & 3172 \\
Ts Bias, K & 0.05 & 0.25 & NA \\
Ts STDE, K & 0.97 & 1.42 & NA \\
Hc Bias, km & NA & NA & 0.29 \\
Hc STDE, km & NA & NA & 1.66 \\
COT Bias & NA & NA & -0.25 \\
COT STDE & NA & NA & 0.79 \\
De Bias, $\mu \mathrm{m}$ & NA & NA & -2.48 \\
De STDE, $\mu \mathrm{m}$ & NA & NA & 11.60 \\
\hline
\end{tabular}
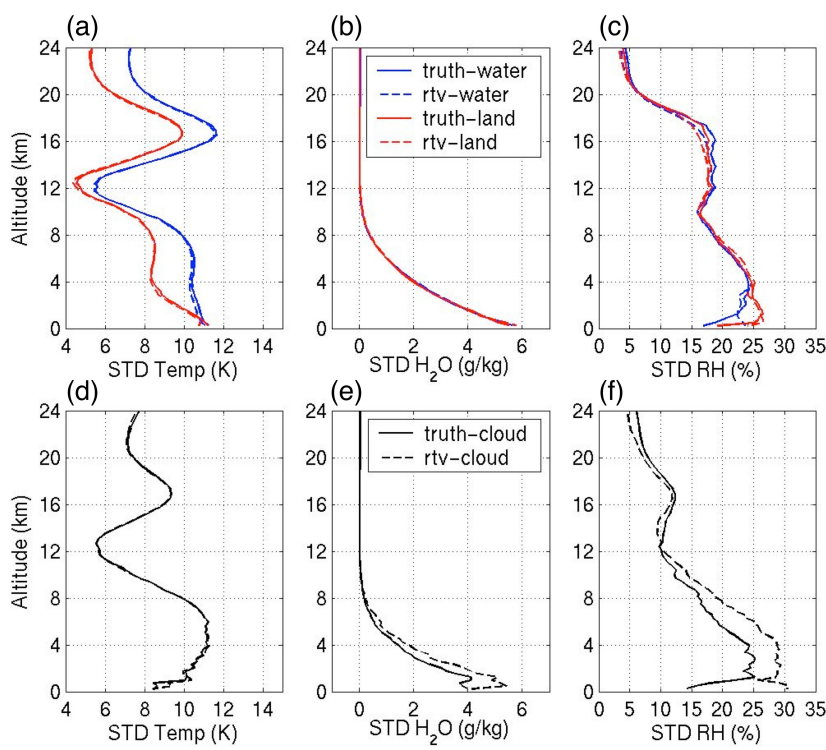

Fig. 5. Standard deviation of atmospheric temperature and moisture profiles of the retrieval testing dataset. Cloud-free atmospheric conditions are plotted in panels $(\mathbf{a}-\mathbf{c})$; profiles over water and land are plotted in red and blue, respectively. Cloudy atmospheric conditions are plotted in panels $(\mathbf{d}-\mathbf{f})$.

"truth." The diversity of the test dataset, as represented by its standard deviation (STD), is compared with that of the retrievals from the radiances simulated for the test dataset. Fig. 5 shows plots of the STD of the test dataset (listed in Table 1) and its associated retrievals, indicating a large diversity of atmospheric conditions in this global coverage test dataset. As shown, variability of the atmospheric profiles is captured by the retrievals; however, the retrieval accuracy is better under cloud-free conditions than under cloudy conditions, especially with the moisture.

\section{JAIVEx Retrievals and Inter-comparisons}

The Houston, Texas based JAIVEx, which took place from 14 April to 4 May 2007, has gathered a wealth of useful (a) GOES-12 IR image

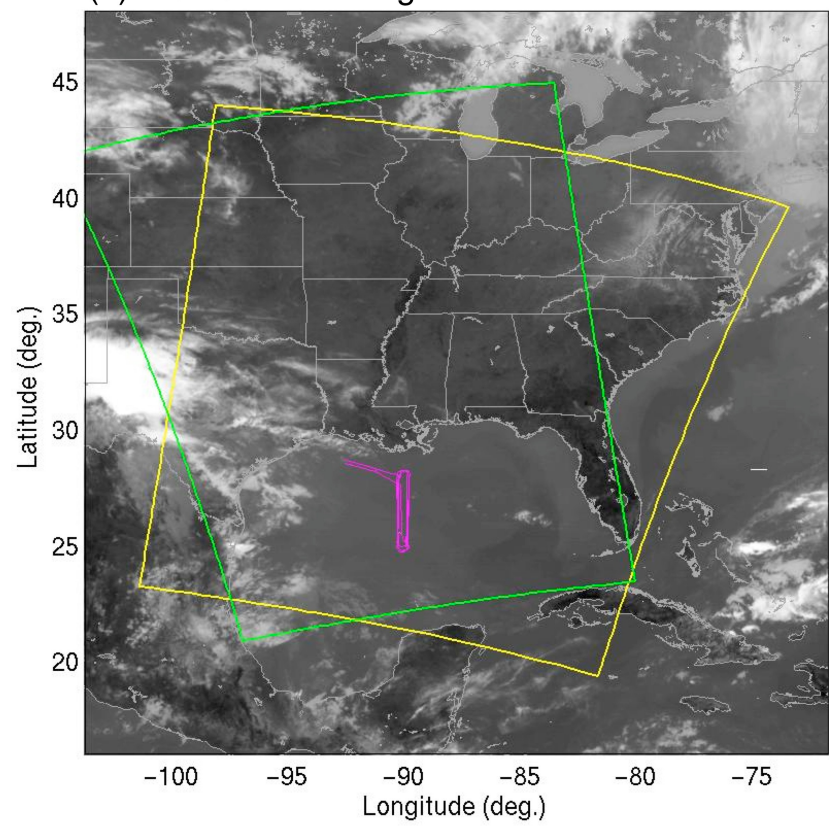

(b) GOES-12 visible image

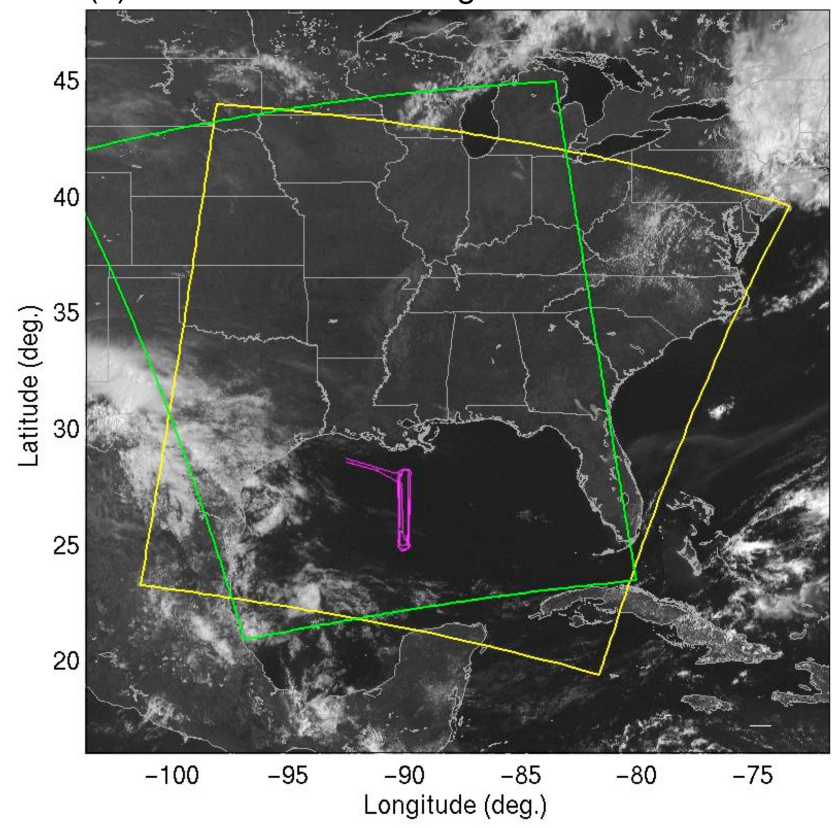

Fig. 6. GOES-12 IR and visible images shown in panels (a) and (b) with WB-57 aircraft flight track (in magenta), IASI granule (in yellow), and AIRS granule (green) boundaries.

datasets for validation of radiance observations and meteorological products from the IASI. Two aircraft, the NASA WB-57 and the Facility for Airborne Atmospheric Measurements (FAAM) BAe-146 (Taylor et al., 2008), operated together for several Metop-A under-flights. Flights were made over the Gulf of Mexico and over the US Department of Energy Oklahoma ARM-CART (Atmospheric 

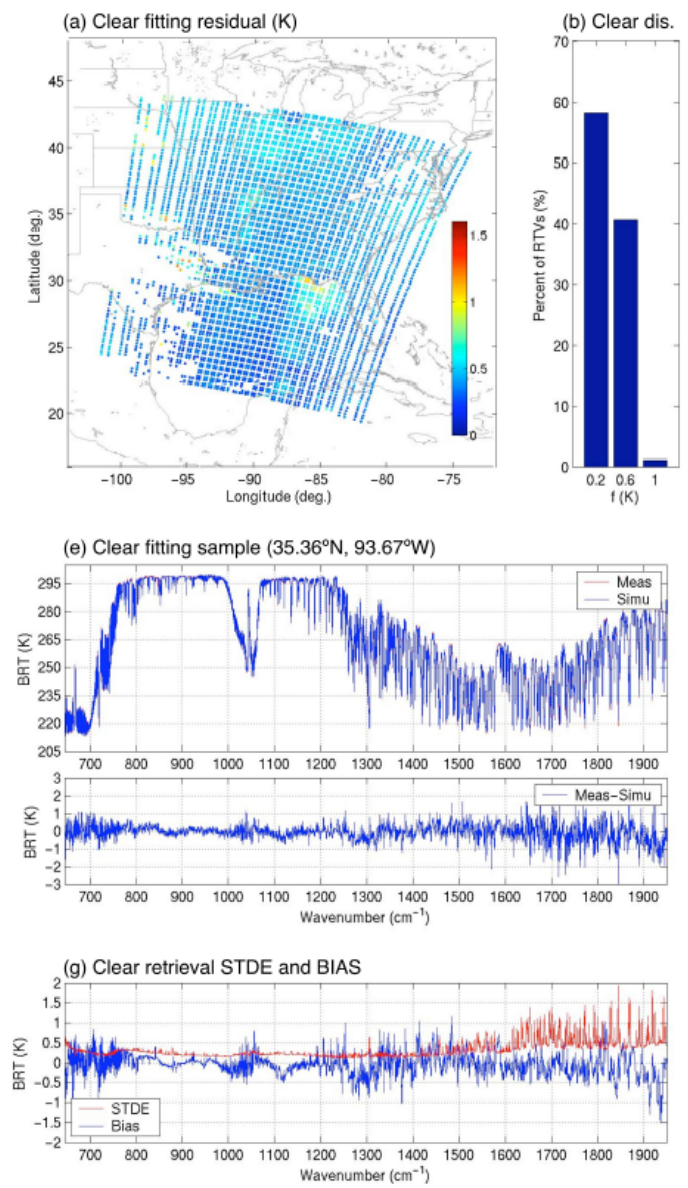
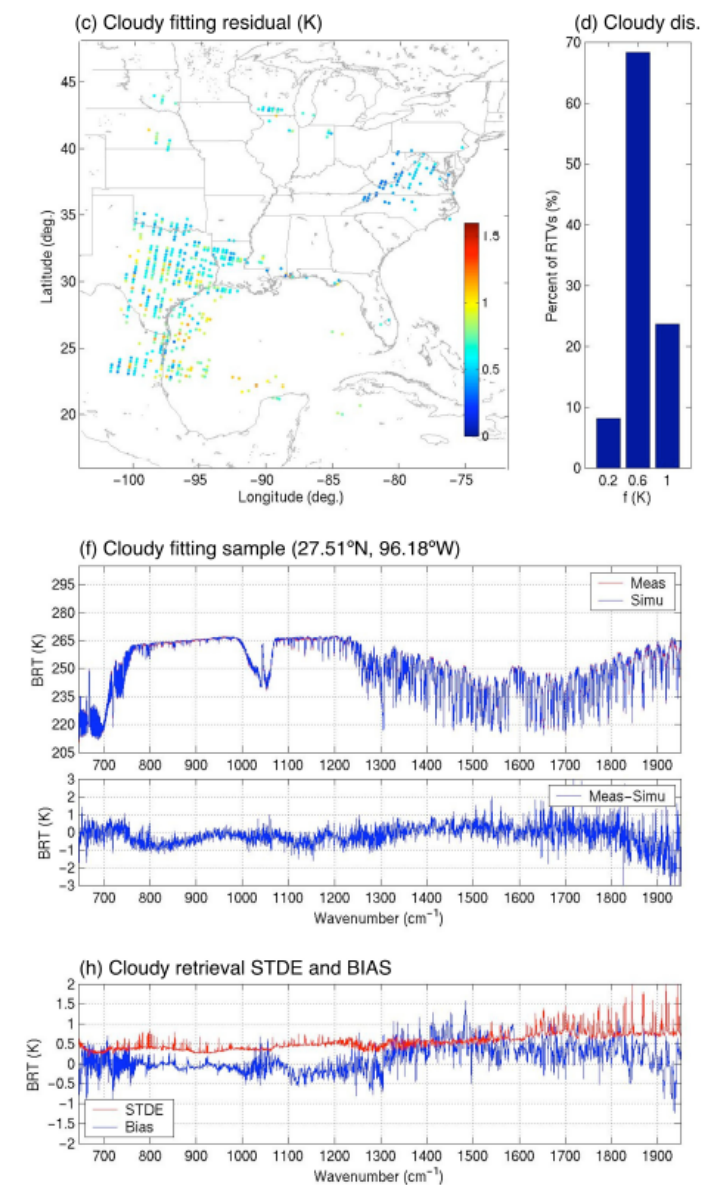

Fig. 7. Retrieval fitting residuals and their distribution under clear conditions are in panels (a) and (b) while cloudy conditions are in panels (c) and (d); samples of spectral fitting of IASI bands 1 and 2 are in panels (e-f) for clear and cloudy conditions, respectively; statistical bias and a STDE are in panels ( $\mathbf{g}-\mathbf{h})$ for clear and cloudy conditions, respectively (see text).

Radiation Measurement-Cloud And Radiation Test-bed) site. Radiosondes were launched from the ARM-CART site during Metop-A overpasses. During the JAIVEx, the NASA WB-57 aircraft, together with the UK FAAM BAe-146 aircraft, made flights dedicated to IASI validation. Ultraspectral instruments, such as the NAST-I, flew on the NASA WB57 aircraft to provide measurements for IASI radiance and retrieval intercomparison (Larar et al., 2009). Numerous insitu sensors and remote sensing instruments flew on the BAe146 aircraft, and dropsondes were released from the BAe-146 during under flights of IASI. Most JAIVEx data have been processed and geophysical parameters retrieved from IASI, AIRS, and NAST-I, which can be used to assess both retrieval accuracy and instrument performance. However, only the results from 29 April 2007 are presented here to illustrate the IASI radiometric performance and retrievals obtained during the JAIVEx. Both the WB-57 and BAe-146 aircraft flew for a period of time long enough to under fly the Metop-A and the Aqua satellites. Fig. 6a and b show GOES-12 infrared and visible images taken at 15:33 UTC. The IASI overpass was around 15:48 UTC with a granule of data being obtained within the yellow box and the AIRS overpass was around 19:30 UTC with a granule of data being collected within the green box. The NASA WB-57 (track with magenta line) and the FAAM BAe-146 aircraft were flown over the same location from 15:30 to 19:20 UTC. Comparisons are presented here for atmospheric soundings obtained from satellite ultraspectral instrumental measurements, airborne ultraspectral FTS measurements, and dedicated dropsondes and radiosonde observations.

\subsection{Retrieval consistency}

These retrievals have gone through quality control (i.e., retrieval consistency checks) based on a standard deviation of the difference between the measured and retrieval simulated brightness temperature over the spectrum of physical retrieval channels, hereafter denoted as $\mathrm{f}$, spectral radiance fitting residual. This retrieval fitting residual is strongly dependent on the accuracy of retrieval parameters. The clearsky and/or cloud-undetected conditions are hereafter called 
"clear" in those conditions where retrievals are almost unaffected by the clouds. Figure 7a-d show plots of the fitting residuals, and their distributions, in the categories of clear and cloudy conditions identified by the retrieval. It is noted that they are limited to fitting residuals of less than $1.2 \mathrm{~K}$. There are 131 out of 5400 profiles in this granule that have their fitting residuals greater than $1.2 \mathrm{~K}$; most of them are due to low quality observed radiances and some complexity of cloudy conditions which are just too hard to handle with this retrieval system. Nevertheless, the percentage with a fitting residual greater than $1.2 \mathrm{~K}$ is very small, i.e., less than $3 \%$ for this case. Fitting residuals shown in Fig. $7 \mathrm{a}$ and $\mathrm{b}$ for clear conditions are much smaller than fitting residuals shown in Fig. $7 \mathrm{c}$ and $\mathrm{d}$ for cloudy conditions. This is expected since there are more variables to be retrieved under cloudy conditions, and the radiative transfer model error (also considered as "equivalent instrument noise") is increased when the cloud model is introduced. Radiance fitting residual samples from both clear and cloudy cases are shown in Fig. 7e and f, respectively; and statistical analyses producing a bias and a STDE over 4786 clear and 483 cloudy samples are plotted in Fig. $7 \mathrm{~g}$ and h, respectively. It is noted that the fitting residual threshold of $1.2 \mathrm{~K}$ used for this case is arbitrary such that there may be a few retrievals with suboptimal accuracy, especially if cloud misdetection occurs. However, this threshold can be modified by the user to filter erroneous data or more simply used as a retrieval quality indicator.

\subsection{Cloud and surface parameters}

IASI retrievals include effective cloud microphysical properties, surface parameters (under clear conditions), and atmospheric temperature and moisture profiles. Cloud microphysical parameters retrieved from the IR ultraspectral data are "effective" in the sense that they depend on instrument characteristics (e.g., FOV size) and spectral dependence of the infrared sensitivity of the cloud property. For instance, observed IR radiance has a limited sensitivity to variation of cloud optical depth for large values, i.e., a retrieved "effective" optical depth of an opaque cloud can be quite different from the real optical depth of the cloud. Although the cloud retrieval algorithm has been evaluated with aircraft data (e.g., dropsondes and CPL) from the THORPEX Atlantic Regional Campaign (ATReC) (Zhou et al., 2007a), more validations for diverse cloud conditions are desired to give definitive conclusions regarding the retrieval accuracy. Unfortunately, cloud parameters derived from the JAIVEx radiance spectra cannot be thoroughly validated because extensive cloud truth data is not available. However, IASI retrieved cloud distributions and effective cloud heights (Fig. 8a) can be graphically validated using GOES-12 images (i.e., Fig. 6a and b). Retrieved effective cloud optical depth and particle size (in diameter) are plotted in Fig. 8b and c. It is found that cloud detection with IASI is less accurate for low cloud top heights (i.e., less than $3 \mathrm{~km}$ ) over the water. This is due to the rel-
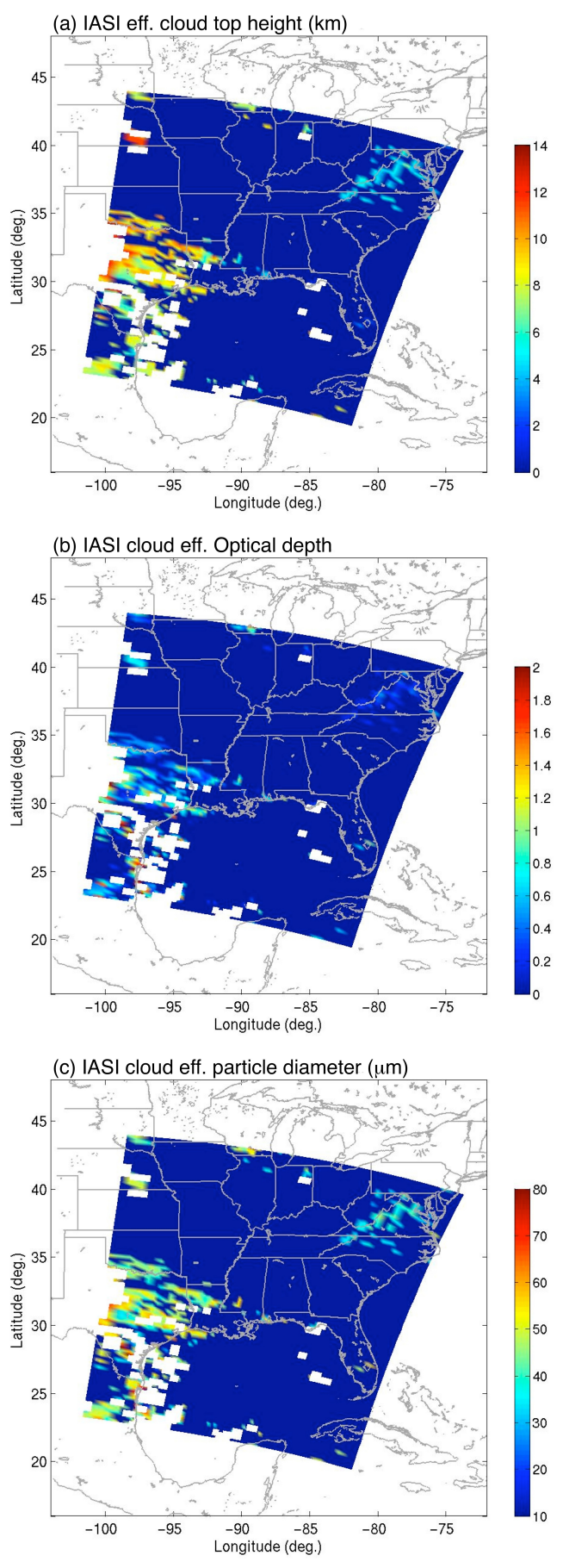

Fig. 8. IASI retrieved cloud height, optical depth, and particle size are in panels $(\mathbf{a}-\mathbf{c})$, respectively (see text).

atively poor contrast between the cloud temperature and the underlying sea surface skin temperature. Detailed investigations are currently underway to improve the retrieval accuracy for this situation.

Surface parameters include surface skin temperature and emissivities retrieved with IASI. These parameters are 
(a) IASI Surfacc Skin Temperature (K)
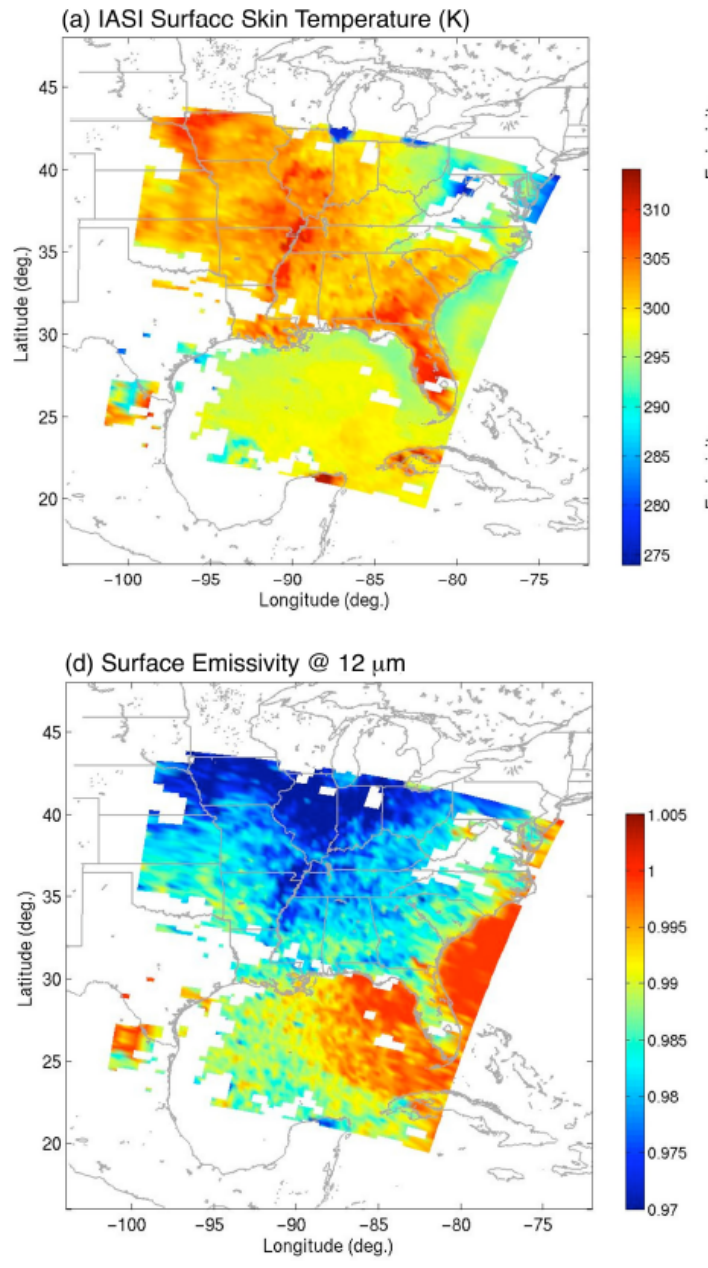
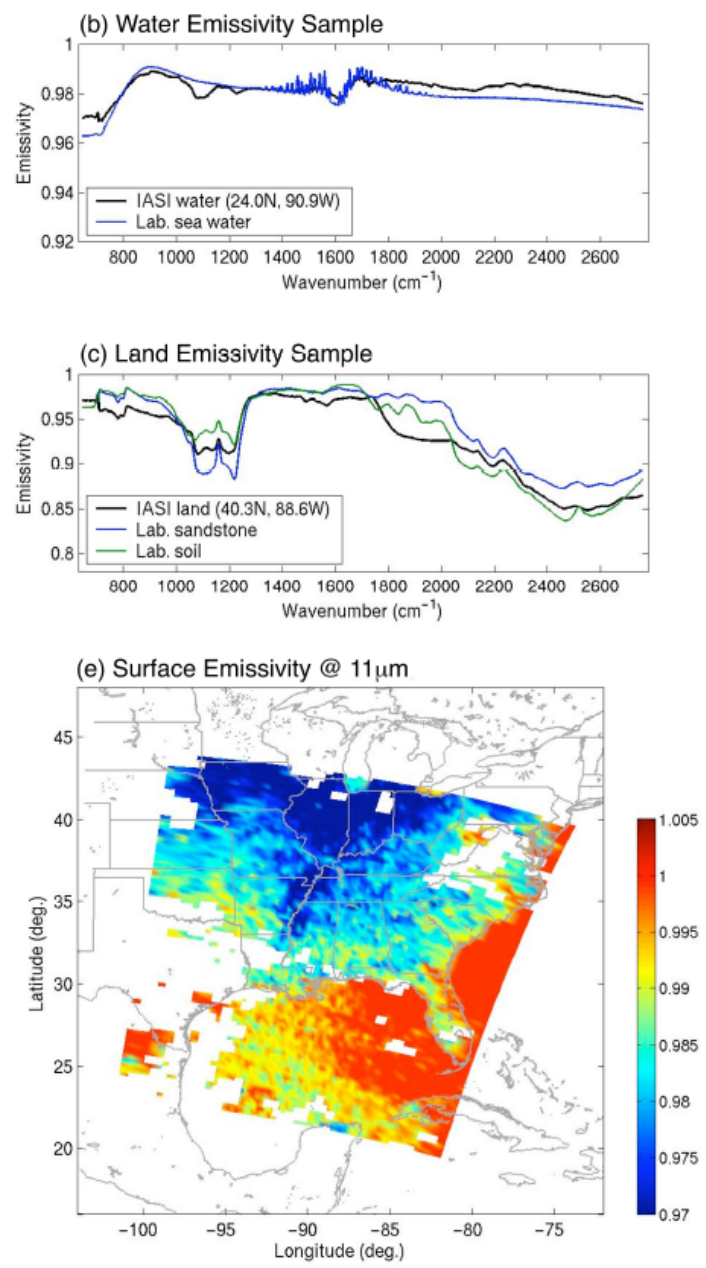

Fig. 9. Surface parameters retrieved from IASI. Panel (a) is surface skin temperature, panels (b, c) are samples of emissivity spectra of water and land, respectively, and panels (d-e) are emissivity distributions at $12-\mu \mathrm{m}$ and $11-\mu \mathrm{m}$, respectively. Notice that white areas were covered with clouds.

critical in obtaining accurate atmospheric profiles near the surface, especially over land where emissivities have a larger variation (Zhou et al., 2006; Zhou et al., 2007a). Fig. 9 plots surface skin temperature and samples of emissivity images. This case was made with the BAe-146 aircraft flying as low as $30 \mathrm{~m}$ above the sea; the sea surface temperature (SST) and emissivity are observed with the Airborne Research Interferometer Evaluation System (ARIES) (e.g., Newman et al., 2005; Taylor et al., 2008). NAST-I and ARIES observations within the IASI FOV are used for the intercomparison. IASI retrieved skin temperature over the water $\left(27.07^{\circ} \mathrm{N}, 90.53^{\circ} \mathrm{W}\right)$ is $297.33 \mathrm{~K}$. This is within $0.5 \mathrm{~K}$ of the NAST-I, ARIES, and nearby buoy (station 42362 at $27.80^{\circ} \mathrm{N}, 90.67^{\circ} \mathrm{W}$ ) water temperature measurements of 297.82 K, 297.77 K, and 297.15 K, respectively. A sample of the water emissivity spectrum retrieved from IASI radiances is plotted in Fig. 9b together with a laboratory measured seawater emissivity spectrum. Land surface skin temperature and emissivity have not been evaluated because of lack of ground truth data and the non-homogeneity of the land surface within the IASI FOV $(12 \mathrm{~km})$. However, it is evident that the land emissivity distributions differ from that of water. The small variation of water surface emissivity is expected due to its surface wind speed dependence. A sample of land emissivity, for a bare-soil spot, is plotted in Fig. 9c along with a laboratory measurement of soil and sandstone emissivity. Surface emissivity images at 12 and $11 \mu \mathrm{m}$ are plotted in Fig. 9d and e, respectively, to reveal the spectral dependence on underlying surface type.

\subsection{Atmospheric temperature and moisture profiles}

Atmospheric temperature and moisture distributions have been retrieved from IASI radiance measurements and validated through comparison with radiosondes, dropsondes and the retrievals from NAST-I and AIRS. Samples of the moisture field (relative humidity) retrieved from IASI measurements for selected vertical and horizontal cross sections are 

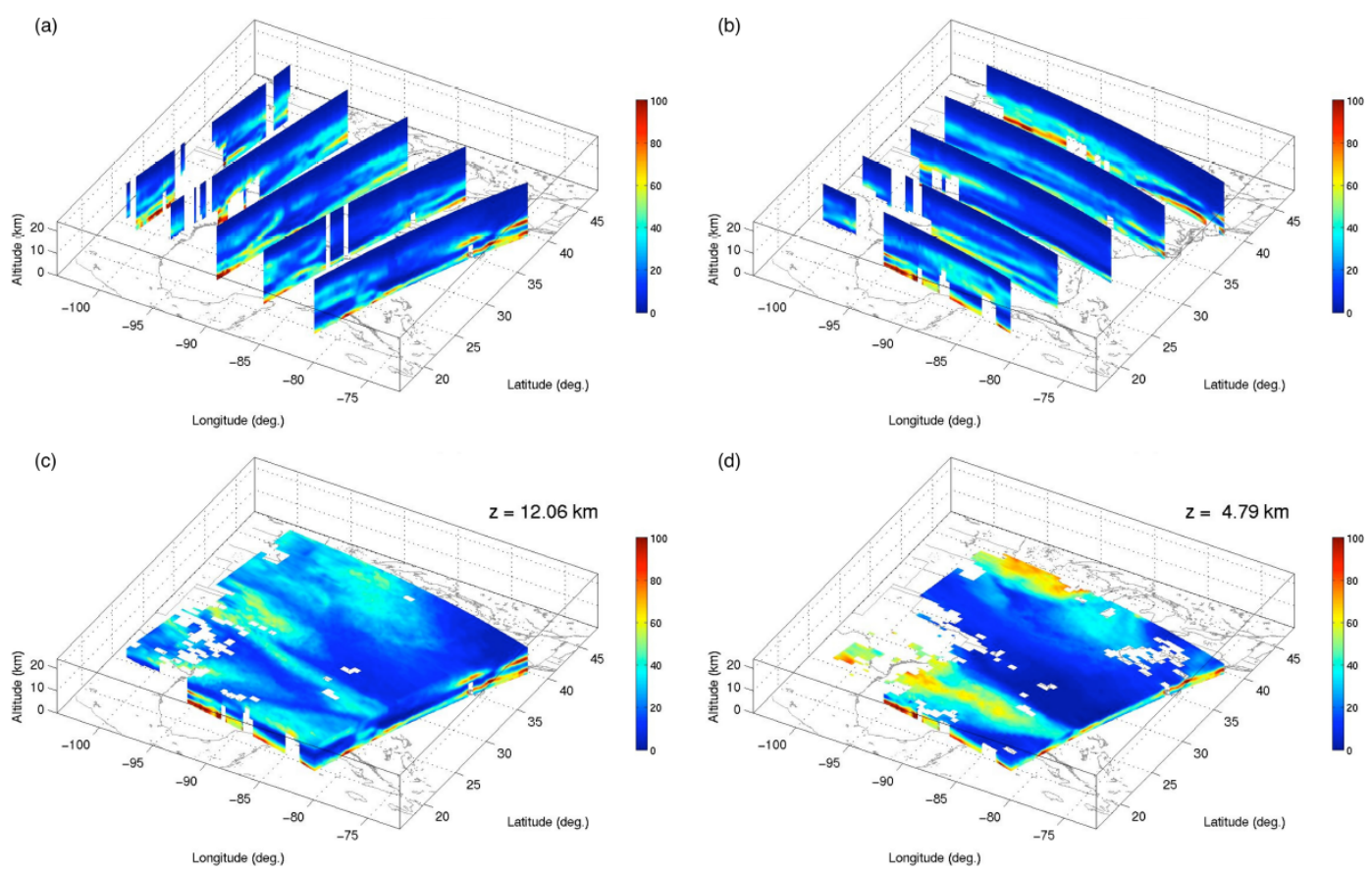

Fig. 10. Relative humidity distribution retrieved from IASI radiance spectra. Panels (a-b) plot the vertical cross sections along and across the satellite track, and panels (c-d) plot the horizontal cross sections at an altitude of $12.06 \mathrm{~km}$ and $4.79 \mathrm{~km}$ respectively.

shown in Fig. 10. A coherent distribution is shown even though the retrieval is performed independently for each individual FOV without any correlation between the neighboring FOVs. Retrievals over the continental US were compared to the radiosonde observations. Selected retrievals vs. radiosondes plots are shown in Fig. 11. It is noted that the IASI observations were made at approximately 15:48 UTC (i.e., 10:48 a.m. local time) while the radiosondes were launched at 12:00 UTC (i.e., 7:00 a.m. local time). The bias and STDE of these temperature and relative humidity sounding profiles are plotted in Fig. 12; however, these comparisons are not to be used to identify the retrieval error and/or accuracy because of unknown field evolution, especially for rapidly changing moisture and cloud conditions. The difference between retrieval and radiosonde is due to a combination of atmospheric temporal variation in addition to the errors in both the retrievals and the radiosondes. In other words, atmospheric evolution characteristics near the radiosonde location could be subtle or obvious. However, these intercomparisons, in conjunction with thermodynamic field retrieved with IASI (e.g., Fig. 10), indicate that atmospheric variations from location-to-location are captured with IASI observations.

In order to obtain coincident sounding profiles for retrieval validation, the NASA WB-57 and FAAM BAe-146 aircraft flew under the Metop-A satellite to provide NAST-I radiance observations very similar to IASI and dropsonde observations. Figure 13a-b show cross-sections of temperature deviation from their granule mean and relative humidity $(\mathrm{RH})$; geophysical locations of the cross section (dashed curve) are plotted in Fig. 13c. One radiosonde launched at 12 UTC near the track (i.e., cross section) is also plotted in Fig. 13d against a co-located IASI retrieval, despite there being a several hour gap between the IASI and radiosonde observations. Sondes were dropped from BAe-146 aircraft at the Metop-A overpass time. Two of these dropsondes, one at the most southern and the other at the most northern flight locations shown on the map (Fig. 13c), are plotted in Fig. 13e and $\mathrm{f}$ against co-located IASI retrievals. Although these locations are not far apart, each individual comparison is made for a very different atmospheric condition. IASI retrievals captured the atmospheric variations, especially for water vapor, between these locations. The variation of water vapor from the upper atmosphere down through the boundary layer to the surface is captured as confirmed by the dropsonde and radiosonde observations. The differences between IASI retrievals and dropsonde observations are within the accuracy estimated in Sect. 2. Large peak-to-peak differences are due to the higher vertical resolution of dropsondes, the difference being within the retrieval accuracy estimated in Sect. 2 when layer averaged profiles are compared (not shown here).

Observations with AIRS on board the Aqua satellite are also used to validate the atmospheric spatial variation observed with IASI, despite their different measurement time between 15:48 UTC (i.e., 10:48 a.m. local time) for IASI and 19:30 UTC (i.e., 02:30 p.m. local time) for AIRS observations. AIRS retrievals are obtained with the same algorithm as described in Sect. 2. In order to make a comparison 

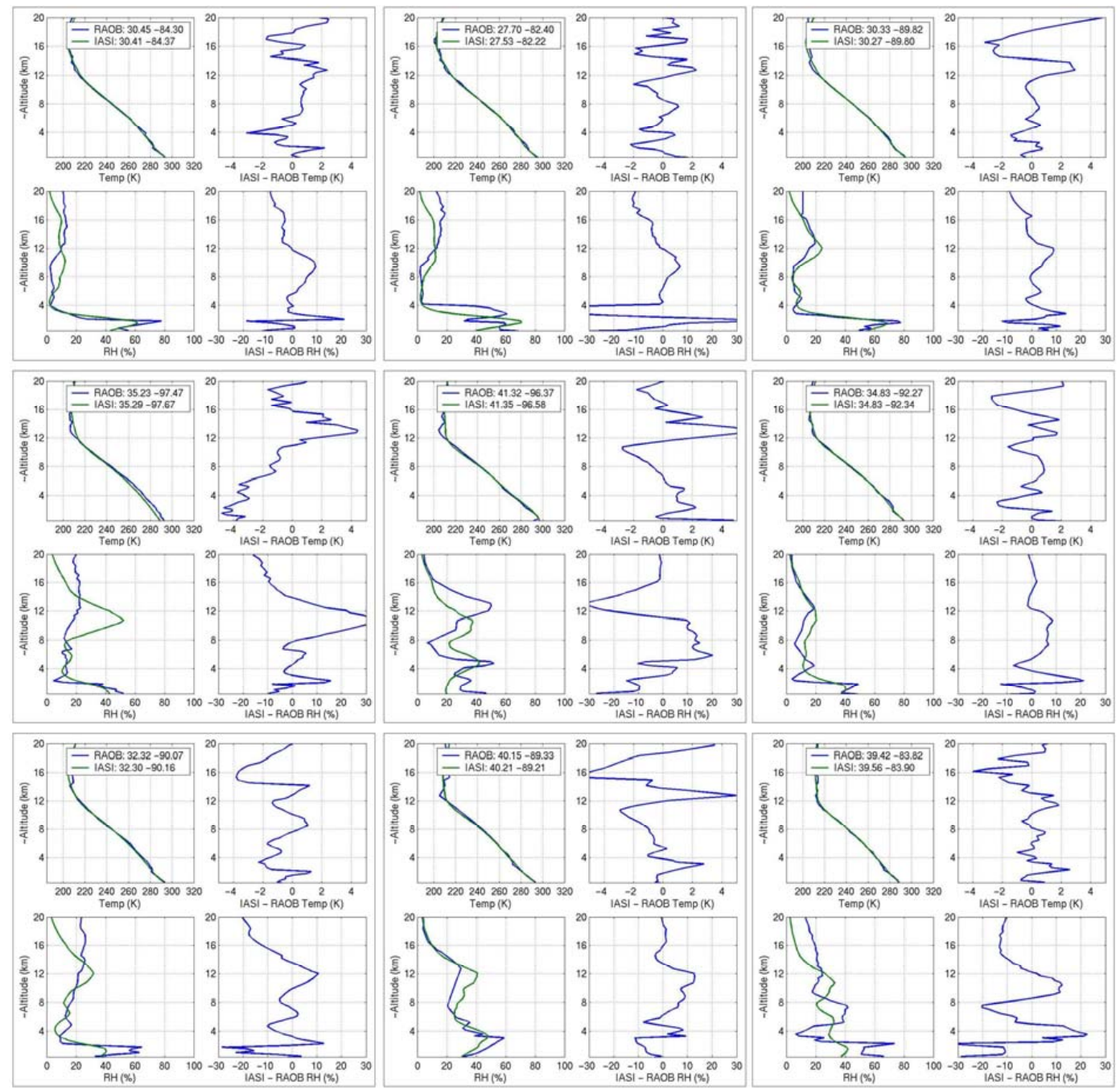

Fig. 11. Selected retrievals (15:48 UTC) vs. radiosondes (12:00 UTC) over continental US.
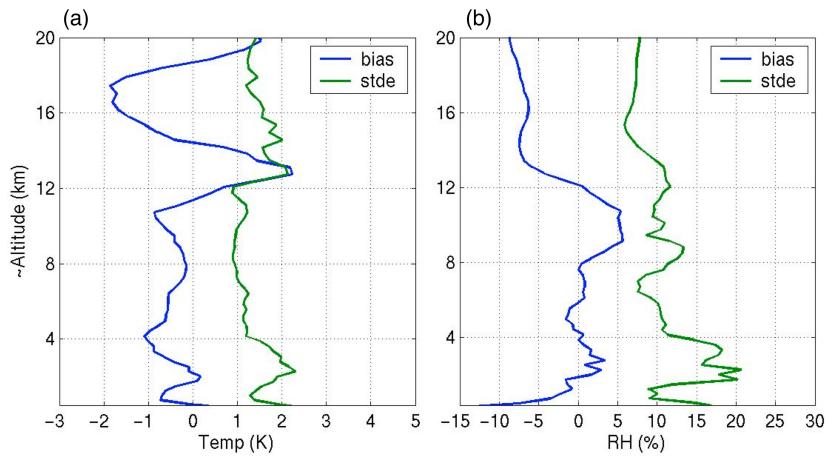

Fig. 12. The bias and STDE of temperature and relative humidity profiles from a total of 16 IASI retrievals and radiosondes (some are plotted in Fig. 11). between IASI and AIRS at the same geophysical location within a common boundary shown in Fig. 6, AIRS retrievals are interpolated to IASI FOVs as shown in Fig. 14a-c, with a cross section at the same geographical locations as that of IASI shown in Fig. 13. The differences between IASI and AIRS retrievals are also plotted in Fig. 14d-f. Very similar spatial distributions of temperature and moisture cross sections are shown despite the diurnal effect (or temporal difference) that contributes to a warmer boundary temperature found in the AIRS retrieval, especially over land. A higher land surface temperature is greatly pronounced in the AIRS observation while the sea surface temperature remained almost the same. Instrument measurement performance, such as spectral resolution and noise level, also contribute to the retrieval performance and difference between AIRS and IASI results. Nevertheless, in this particular case for the period between the IASI and AIRS observations, the field evolution is subtle while the atmospheric variation from location to location is strong as shown by both the IASI and AIRS retrievals. 

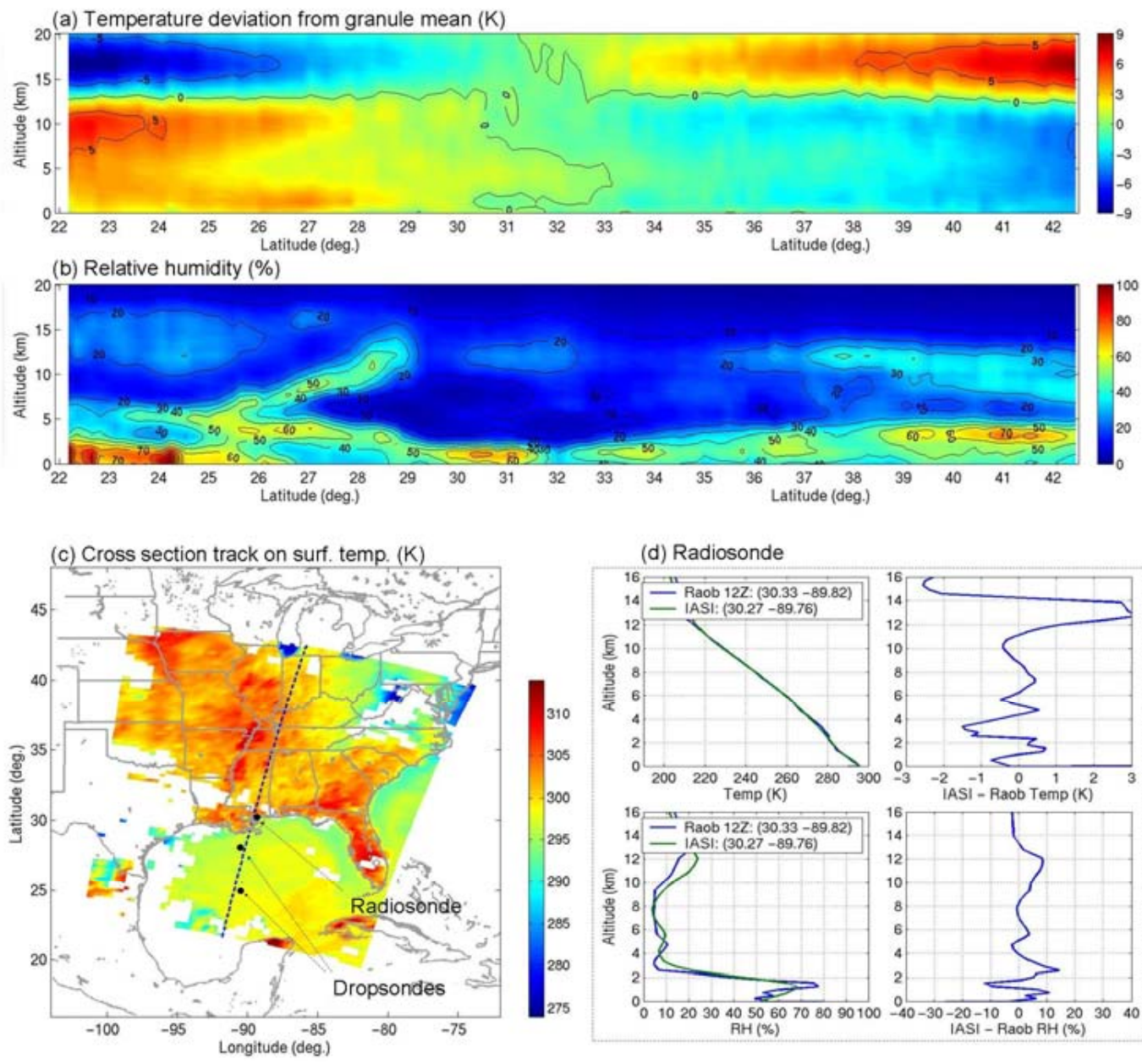

(d) Radiosonde
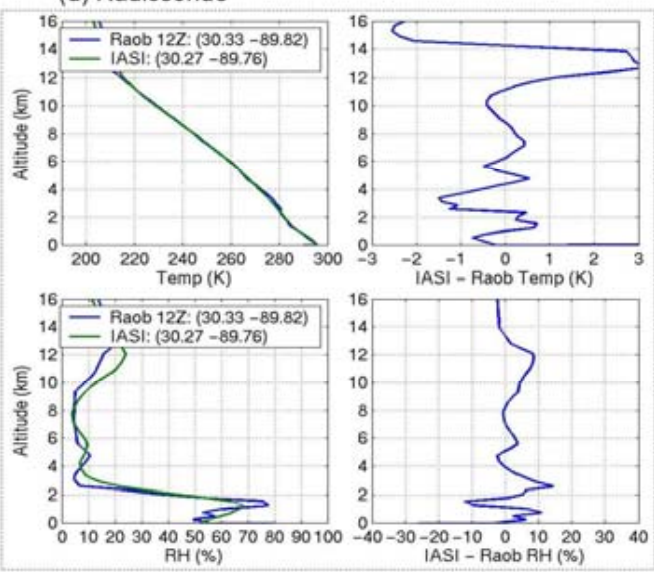

(e) Dropsonde \#1
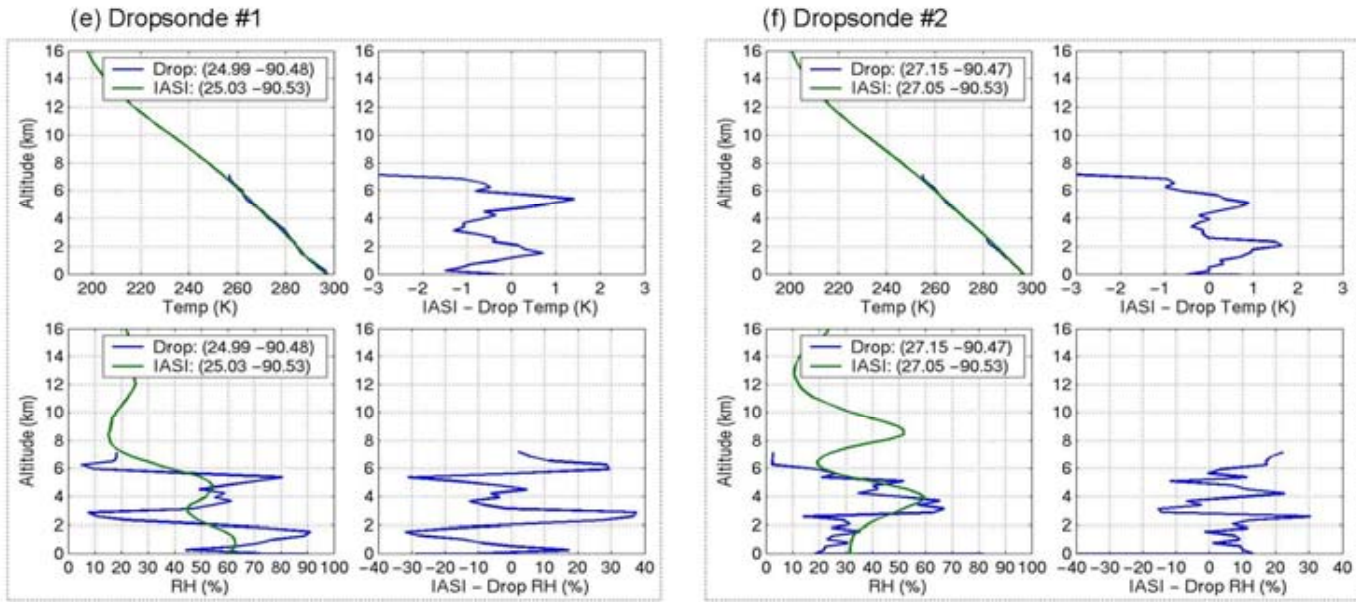

Fig. 13. IASI cross sections of (a) temperature deviation from the mean and (b) relative humidity along the cross section track shown in the dashed curve on (c) surface skin temperature map. Locations of two dropsondes and of one radiosonde near to the track are also shown. Panels (d-f) plot the inter-comparisons between the sondes and IASI retrievals. 

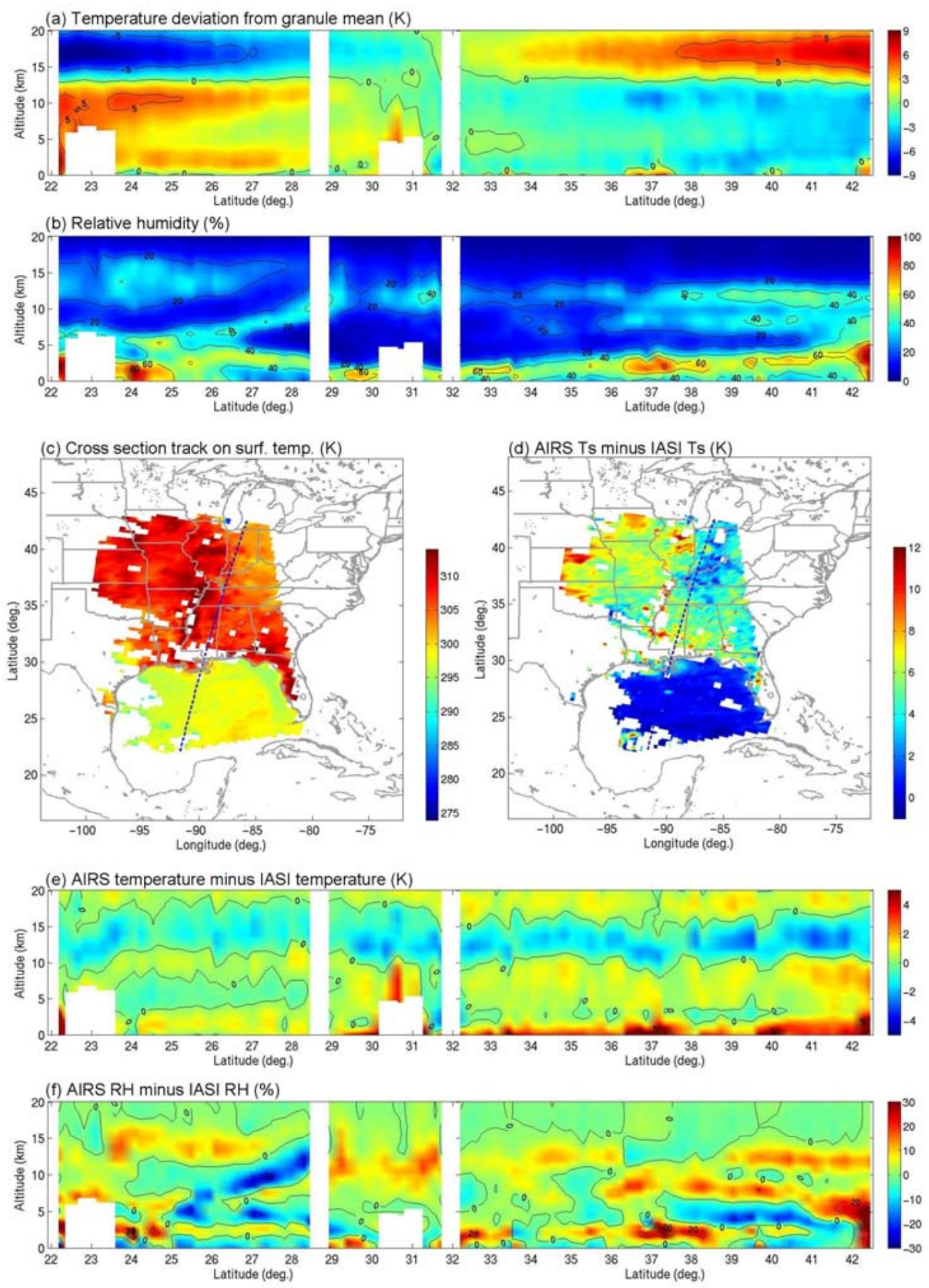

Fig. 14. AIRS cross sections of (a) temperature deviation from the mean and (b) relative humidity along the cross section track shown in the dashed curve on (c) surface skin temperature map. The differences between AIRS and IASI in surface temperature (Ts), temperature, and relative humidity $(\mathrm{RH})$ are found in panels $(\mathbf{d}-\mathbf{f})$, respectively. 
(b) NAST-I: $15: 30-19: 22$ ( 8 legs)
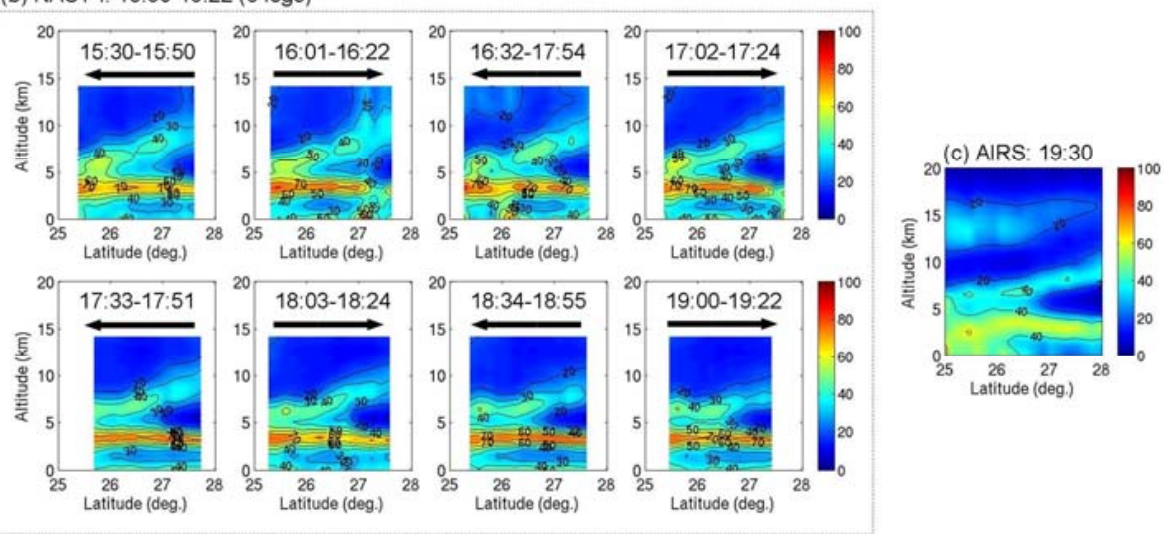

Fig. 15. (a) IASI RH cross-section near aircraft flight domain, (b) NAST-I RH shown as a function of time: aircraft flight direction of each leg is shown by the arrow and the flight leg duration (in UTC) is labeled, and (c) AIRS RH cross-section interpolated to IASI FOV locations.
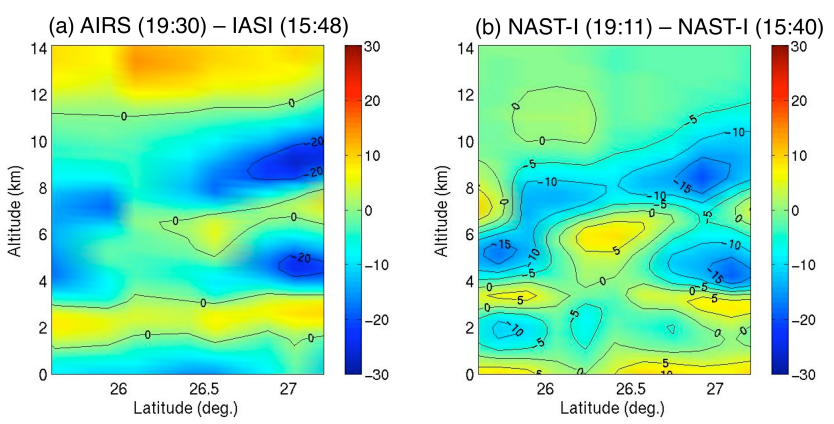

Fig. 16. RH evolution characteristic between AIRS and IASI measurements observed by (a) AIRS at 19:30 UTC and IASI at 15:48 UTC, and (b) by NAST-I at 19:11 UTC and 15:40 UTC.

The WB-57 aircraft IASI under-flights within the cross sections shown in Figs. 13 and 14 are used to verify the subtle field evolution that occurred between the time of the IASI and AIRS observations. NAST-I relative humidity cross-sections are plotted in Fig. 15 as a function of time. The relative humidity difference between AIRS and IASI is plotted in Fig. 16a and compared with that observed by NAST-I plotted in Fig. 16b (i.e., the difference between Leg 1 and Leg $8)$. The difference is mainly due to (1) instrumental differences between IASI (Fig. 15a) and AIRS (Fig. 15c), (2) spatial resolution differences between NAST-I and IASI (and/or AIRS), and (3) retrieval uncertainty including radiative transfer model differences (i.e., SARTA for AIRS and IASI while OSS for NAST-I). Nevertheless, these differences are within the goal of RH retrieval accuracy. The spatial characteristics of the field are very similar between NAST-I, IASI, and AIRS. The temporal variation between IASI and AIRS observation times is revealed by NAST-I measurements.

\section{Summary}

The international experiment, JAIVEx, was successfully conducted for validating ultraspectral satellite measurements. Experimental data were collected during the campaign; these data are used for IASI and AIRS geophysical product validation and for intercomparison of these products accounting for time discrepancies. A state-of-the-art retrieval algorithm, dealing with both clear and cloudy conditions, has been developed and applied to IASI and AIRS radiance measurements. Initial validation using JAIVEx data indicates that fine vertical structure of atmospheric field is retrieved with satellite IR ultraspectral remote sensors. Surface, cloud, and atmospheric structure and variation are captured in IASI retrievals. AIRS retrievals are interpolated to the IASI horizontal resolution for inter-comparison at the same geophysical locations; a temporal variation between AIRS and IASI observations is considered and verified with JAIVEx aircraft observations to account for atmospheric variation within the temporal gap between the two satellites. First results show that both IASI and AIRS have a similar vertical resolving power with atmospheric spatial structure being captured by both instruments. JAIVEx has provided a first-hand validation dataset, which is being used for a rapid evaluation of IASI measurement capability and the further development of its data processing systems. Algorithm improvement and correct implementation is still on going especially in the area of surface emissivity and cloudy retrieval. However, several conclusions can be made from this case study. Very similar surface and atmospheric spatial structures, shown in Figs. 13-15, were retrieved from IASI, AIRS, and NAST-I observations. The surface properties over water are retrieved within the expected accuracy and compared favorably with observations by all instruments from the variety of different platforms, i.e., $0.5 \mathrm{~K}$ and 0.01 for SST and emissivity, respectively (see Sect. 3.2). General retrieval product agreement 
is obtained in that the standard deviation of differences is under $1 \mathrm{~K}$ for temperature, less than $10 \%$ for $\mathrm{RH}$ above the terrestrial boundary layer (TBL), and 10 to $20 \%$ for RH in the TBL (see Sect. 3.3). This study indicates that IASI radiance measurements meet the requirements of Level 2 products with respect to the product accuracy found in the EPS End User Requirements Document (EURD). Additional validation analyses for both clear and cloudy conditions are ongoing to provide more definitive conclusions. Nevertheless, fine-scale atmospheric horizontal features with high vertical resolution from satellite global observations with advanced ultraspectral instruments have been realized for the first time.

Acknowledgements. The authors greatly appreciate the contributions of the NASA Langley Research Center, the Space Science and Engineering Center of the University of Wisconsin - Madison, and the UK Met Office. The NAST-I program is supported by the NPOESS Integrated Program Office, NASA Headquarters, and NASA Langley Research Center. The FAAM is jointly funded by the UK Met Office and the Natural Environment Research Council. IASI has been developed and built under the responsibility of the Centre National d'Etudes Spatiales (CNES). It is flown onboard the Metop satellites as part of the EUMETSAT Polar System. The IASI L1 data are received through the Unified Meteorological Archival and Retrieval Facility (UMARF) of EUMETSAT.

Edited by: A. Richter

\section{References}

Aires, F., Chedin, A., Scott, N. A., and Rossow, W. B.: A regression neural net approach for retrieval of atmospheric and surface temperatures with the IASI instrument, J. Appl. Meteorol., 41, 144-159, 2002.

Aumann, H. H., Chahine, M. T. Gautier, C., Goldberg, M. D., Kalnay, E., McMillin, L. M., Revercomb, H., Rosenkranz, P. W., Smith, W. L., Staelin, D. H., Strow, L., and Susskind, J.: AIRS/AMSU/HSB on the Aqua mission: design, science objective, data products, and processing systems, IEEE T. Geosci. Remote, 41, 253-264, 2003.

Blumstein, D., Chalon, G., Carlier, T., Buil, C., Hebert, P., Maciaszek, T., Ponce, G., and Phulpin, T.: IASI instrument: technical overview and measured performances, SPIE Proc. 5543, 196207, 2004.

Borbas, E., Seemann, S. W., Huang, H.-L., Li, J., and Menzel, W. P.: Global profile training database for satellite regression retrievals with estimates of skin temperature and emissivity, Proc. Int. ATOVS Study Conf. XIV, Beijing, China, CIMSS, University of Wisconsin-Madison, 763-770, 2005.

Chahine, M. T., Pagano, T. S., Aumann, H. H., Atlas, R., Barnet, C., Blaisdell, J., Chen, L., Divakarla, M., Fetzer, E. J., Goldberg, M., Gautier, C., Granger, S., Hannon, S., Irion, F. W., Kakar, R., Kalnay, E., Lambrigtsen, B. H., Lee, S.-Y., Le Marshall, J., McMillan, W. W., McMillin, L., Olsen, E. T., Revercomb, H., Rosenkranz, P., Smith, W. L., Staelin, D., Strow, L. L., Susskind, J., Tobin, D., Wolf, W., and Zhou, L.: AIRS: improving weather forecasting and providing new insights into climate, B. Am. Meteorol. Soc., 87, 911-926, 2006.
Cousins, D. and Smith, W. L.: National Polar-Orbiting Operational Environmental Satellite System (NPOESS) Airborne Sounder Testbed-Interferometer (NAST-I), SPIE Proc., 3127, 323-331, 1997.

Eldering, A., Kahn, B. H., Mills, F. P., Irion, F. W., Steele, H. M., Gunson, M. R.: Vertical profiles of aerosol volume from high spectral resolution infrared transmission measurements: Results, J. Geophys. Res., 109, D20201, doi:10.1029/2004JD004623, 2004.

Hansen, P. C.: Rank-Deficient and Discrete Ill-Posed Problems: Numerical Aspects of Linear Inversion. Society for Industrial and Applied Mathematics [SIAM] Monographs on Mathematical Modeling and Computation \#4, Philadelphia, PA, USA, 247 pp., 1998.

Heymsfield, A. J., Matrosov, S., and Baum, B.: Ice water pathoptical depth relationships for cirrus and deep stratiform ice cloud layers, J. Appl. Meteorol., 42, 1369-1390, 2003.

Klaes, K. D., Cohen, M. Buhler, Y., Schlüssel, P., Munro, R., Luntama, J.-P., Von Engeln, A., Clerigh, E. Ó., Bonekamp, H., Ackermann, J., Schmetz, J.: An introduction to the EUMETSAT Polar System, B. Am. Meteorol. Soc, 88, 1085-1096, 2007.

$\mathrm{Li}, \mathrm{J} .:$ Temperature and water vapor weighting functions from radiative transfer equation with surface emissivity and solar reflectivity, Adv. Atmos. Sci., 11, 421-426, 1994.

Larar, A. M, Smith, W. L., Zhou, D. K., Liu, X., Revercomb, H., Taylor, J. P., Newman, S. M., and Schlüssel, P.: IASI spectral radiance performance validation: case study assessment from the JAIVEx field campaign, Atmos. Chem. Phys., submitted, 2009.

Liu, X., Moncet, J.-L., Zhou, D. K., and Smith, W. L.: A Fast and Accurate Forward Model for NAST-I Instrument, in: Fourier Transform Spectroscopy and Optical Remote Sensing of Atmosphere, 2003 Technical Digest Series OSA, Opt. Soc. Am., Washington, DC, USA, p. 16., 2003.

Ma, X. L., Schmit, T. J., and Smith, W. L.: A nonlinear physical retrieval algorithm - its application to the GOES-8/9 sounder, J. Appl. Meteorol., 38, 501-513, 1999.

Moncet, J. L., Liu, X., Rieu-Isaacs, H., Snell, H., Zaccheo, S., Lynch, R., Eluszkiewicz, J., He, Y., Uymin, G., Lietzke, C., Hegarty, J., Boukabara, S., Lipton, A., and Pickle, J.: Algorithm theoretical basis document (ATBD) for the Cross Track Infrared Sounder (CrIS) environmental data records (EDR), V1.2.3, AER document P882-TR-E-1.2.3-ATBD-03-01, Atmos. Environ. Res., Boston, Mass., USA, 2003.

Newman, S. M., Smith, J. A., Glew, M. D., Rogers, S. M., and Taylor, J. P.: Temperature and salinity dependence of sea surface emissivity in the thermal infrared, Q. J. Roy. Meteor. Soc., 131, 2539-2557, 2005.

Pagano, T. S., Aumann, H. H., Hagan, D. E., and Overoye, K.: Prelaunch and in-flight radiometric calibration of the Atmospheric Infrared Sounder (AIRS), IEEE T. Geosci. Remote, 41, 265-273, 2003.

Pougatchev, N.: Validation of Atmospheric Sounders by Correlative Measurements, Appl. Optics, 47, 4739-4748, 2008.

Rodgers, C. D.: Retrieval of atmospheric temperature and composition from remote measurements of thermal radiation, Rev. Geophys. Space G., 14, 609-624, 1976.

Salisbury, J. W., and D'Aria, D. M.: Emissivity of terrestrial material in the $8-14 \mu \mathrm{m}$ atmospheric window, Remote Sens. Environ., 42, 83-106, 1992. 
Seemann, S. W., Borbas, E. E., Knuteson, R. O., Stephenson, G. R., and Huang, H.-L.: Development of a global infrared land surface emissivity database for application to clear-sky sounding retrievals from multi-spectral satellite radiance measurements, J. Appl. Meteorol. Clim., 47, 108-123, 2008.

Smith, W. L., Zhou, D. K., Huang, H.-L., Li, J., Liu, X., and Larar, A. M.: Extraction of profile information from cloud contaminated radiances, paper presented at the ECMWF Workshop on the Assimilation of High Spectral Resolution Sounders in NWP, June 28-July 1, 2004.

Stamnes, K., Tsay, S.-C., Wiscombe, W., and Jayaweera, K.: Numerically stable algorithm for discrete-ordinate-method radiative transfer in multiple scattering and emitting media, Appl. Optics, 27, 2502-2509, 1988.

Strow, L. L., Hannon, S. E., De Souza-Machado, S., Motteler, H. E., and Tobin, D.: An overview of the AIRS radiative transfer model, IEEE T. Geosci. Remote, 41, 303-313, 2003.

Taylor, J. P., Smith, W. L., Cuomo, V., Larar, A. M., Zhou, D. K., Serio, C., Maestri, T., Rizzi, R., Newman, S., Antonelli, P., Mango, S., Di Girolamo, P., Esposito, F., Grieco, G., Summa, D., Restieri, R., Masiello, G., Romano, F., Pappalardo, G., Pavese, G., Mona, L., Amodeo, A., and Pisani, G.: EAQUATE - An international experiment for hyper-spectral atmospheric sounding validation, B. Am. Meteorol. Soc., 89, 203-218, 2008.

Tikhonov, A. N.: On the solution of incorrectly stated problems and a method of regularization, Dokl. Acad. Nauk. SSSR, 151, 501504, 1963.

Tobin, D. C., Revercomb, H. E., Knuteson, R. O., Lesht, B. M., Strow, L. L., Hannon, S. E., Feltz, W. F., Moy, L. A., Fetzer, E. J., and Cress, T. S.: Atmospheric Radiation Measurement site atmospheric state best estimates for Atmospheric Infrared Sounder temperature and water retrieval validation, J. Geophys. Res., 111, D09S14 doi:10.1029/2005JD006103, 2006.
Twomey, S.: On the numerical solution of Fredholm integral equations of the first kind by inversion of the linear system produced by quadrature, J. Assoc. Comput. Mach., 10, 97-101, 1963.

Weisz, E., Li, J., Li, J., Zhou, D. K., Huang, H., Goldberg, M. D., and Yang, P.: Cloudy sounding and cloud-top height retrieval from AIRS alone single field-of-view radiance measurements, Geophys. Res. Lett., 34, L12802, doi:10.1029/2007GL030219, 2007.

Yang, P., Gao, B. C., Baum, B. A., Hu, Y., Wiscombe, W. J., Tsay, S.-C., Winker, D. M., and Nasiri, S. L.: Radiative Properties of cirrus clouds in the infrared $(8-13 \mu \mathrm{m})$ spectral region, J. Quant. Spectros. Rad., 70, 473-504, 2001.

Zhou, D. K., Smith, W. L., Li, J., Howell, H. B., Cantwell, G. W., Larar, A. M., Knuteson, R. O., Tobin, D. C., Revercomb, H. E., and Mango, S. A.: Thermodynamic product retrieval methodology for NAST-I and validation, Appl. Opt., 41, 6957-6967, 2002.

Zhou, D. K., Smith, W. L., Liu, X., Larar, A. M., Huang, H.-L. A., Li, J., McGill, M. J., and Mango, S. A.: Thermodynamic and cloud parameters retrieval using infrared spectral data, Geophys. Res. Lett., 32, L15805, doi:10.1029/2005GL023211, 2005.

Zhou, D. K., Larar, A. L., Smith, W. L., and Liu, X.: Surface emissivity effects on thermodynamic retrieval of IR spectral radiance, Proc. SPIE 6405, 64051H, 2006.

Zhou, D. K., Smith, Sr., W. L., Liu, X., Larar, A. M., Mango, S. A., and Huang, H.-L.: Physically retrieving cloud and thermodynamic parameters from ultraspectral IR measurements, J. Atmos. Sci., 64, 969-982, 2007a.

Zhou, D. K., Smith, W. L., Cuomo, V., Taylor, J. P., Barnet, C. D., Di Girolamo, P., Pappalardo, G., Larar, A. M., Liu, X., Newman, S. M., Lee, C., and Mango, S. A.: Retrieval validation during the European Aqua Thermodynamic Experiment, Q. J. Roy. Meteor. Soc. 133, 203-215, 2007b. 